\title{
MORTALITY IN YOUNG CHILDREN IN THE CITY OF ABERDEEN DURING THE FIFTY YEARS 1900-1949
}

\author{
BY \\ JOHN CRAIG \\ From the Department of Child Health of the University of Aberdeen
}

Much has been written and spoken concerning the mortality of infancy, but much less has been said about that of the pre-school child. The pre-school period is an important one, and many troubles in childhood and later life can be traced to infections and difficulties experienced during this time. As Sir Charles Newman said: 'A rich harvest will reward careful supervision and nurture at this age period.' To a certain extent, these children have been less studied than those who are younger or older, for unless they come under the care of the family doctor, usually with acute illnesses, they are not supervised medically; and till toddlers' clinics and nursery schools were instituted, these pre-school children were too old for the child welfare centres, and not old enough for the school medical services.

The fall in the deaths in young children during the last 50 years has been as striking as the fall in infant deaths; and this article is a preliminary study of pre-school child deaths in children in the second, third, fourth, and fifth years of life as recorded in the City of Aberdeen in the 50 years from 1900 to 1949 inclusive. The data are derived chiefly from the excellent annual reports of the Medical Officers of Health, the late Professor Matthew Hay and Dr. J. Parlane Kinloch, and from the present holder of the office, Dr. Harry J. Rae, to whom I am indebted for much information.

The physiology and pathology of the young child are characteristic, and differ from those of the infant and the school child. It may be recalled that the diet is changing, and that milk is no longer the chief food, although still an important one. The growth in height and weight may be slowing down, but there are striking advances in accomplishments, in movement and activity, in contacts with the outside world, and in the growth of personality and adjustment to environment. The young child is losing any immunity to certain infectious diseases that may have been acquired from the mother, and must acquire his own by the painful process of battling with the organisms themselves, or in other instances, such as in diphtheria, by reacting successfully to toxins or vaccines artificially introduced. The body chemistry is still unstable, and the young child remains sensitive to deficiencies in food and vitamins. All these differences are reflected in the mortality rates of the age period.

The population of the City of Aberdeen, 150,906 in 1900, has slowly increased during the century, and in 1949 it was estimated to be 189,314. In 1951 the census reported a population of 182,714 . With the fall in the birth rate, the numbers of children in the four year age period between one and five have not increased, and, indeed, have decreased slightly as is shown in Table 1.

TABLE 1

Numbers of Children between 1 and 5 Years of Age in Aberdeen

\begin{tabular}{c|c}
\hline Year & Number \\
\hline 1901 & 14,758 \\
\hline 1911 & 14,938 \\
\hline 1921 & 10,591 \\
\hline 1931 & 11,396 \\
\hline 1951 & $\begin{array}{c}14.000 \\
\text { (estimated) }\end{array}$ \\
\hline
\end{tabular}

At the beginning of the century, the mortality rates in Aberdeen in the school age period, and to a less extent in the pre-school period, were falling, but the infant mortality was rising, and giving cause for concern and investigation. Measles, whooping cough, diphtheria, and scarlet fever were showing an increasing prevalence but a diminishing mortality. Antitoxin was already being used in hospitals for diphtheria cases, but it was not supplied free before 1906, along with a syringe, swabs, and other necessary equipment, to general practitioners. There was, of course, no specific therapy for the other zymotic diseases. 
TABLE 2

Births, Infant Deaths, Pre-school Age Deaths, and School Age Deaths in City of Aberdeen from 1900 to 1949 INCLUSIVE

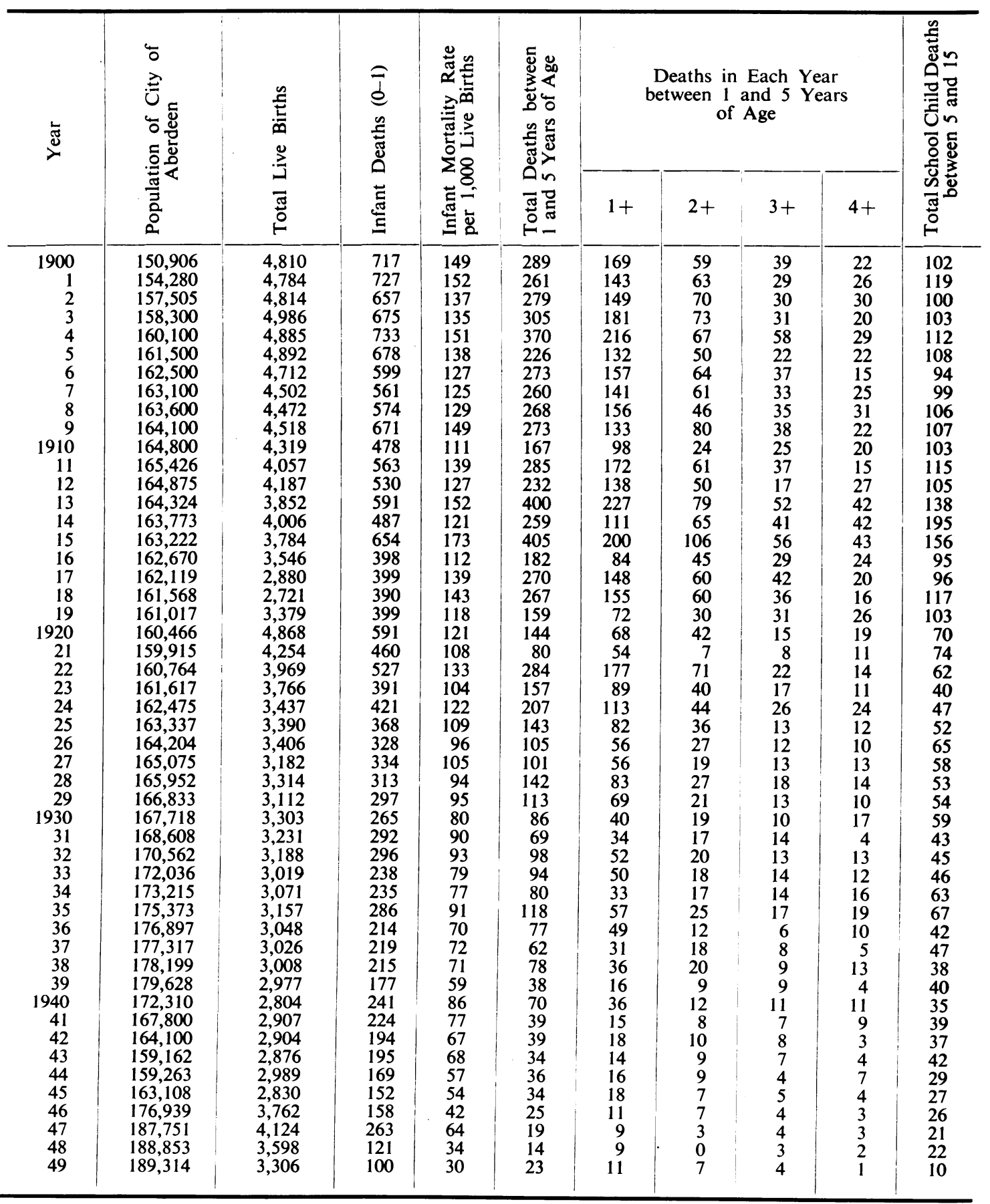


Total Deaths

It will be seen from Table 2 and Fig. 1 that during the half century there has been a tremendous fall in the yearly number of deaths: from 289 in 1900 , to 23 in 1949, and the fall has been well maintained in the last 10 years. Table 4, showing deaths in quinquennial periods, reflects an even more striking
The trends in the mortality rates have been steadily downwards, but their courses have been punctuated by temporary rises, for example, in 1904, 1913, 1915, and 1922. The rises, as will be seen, were largely due to deaths from measles and whooping cough. The worst year of all was 1915 with 405 deaths; measles and whooping cough were

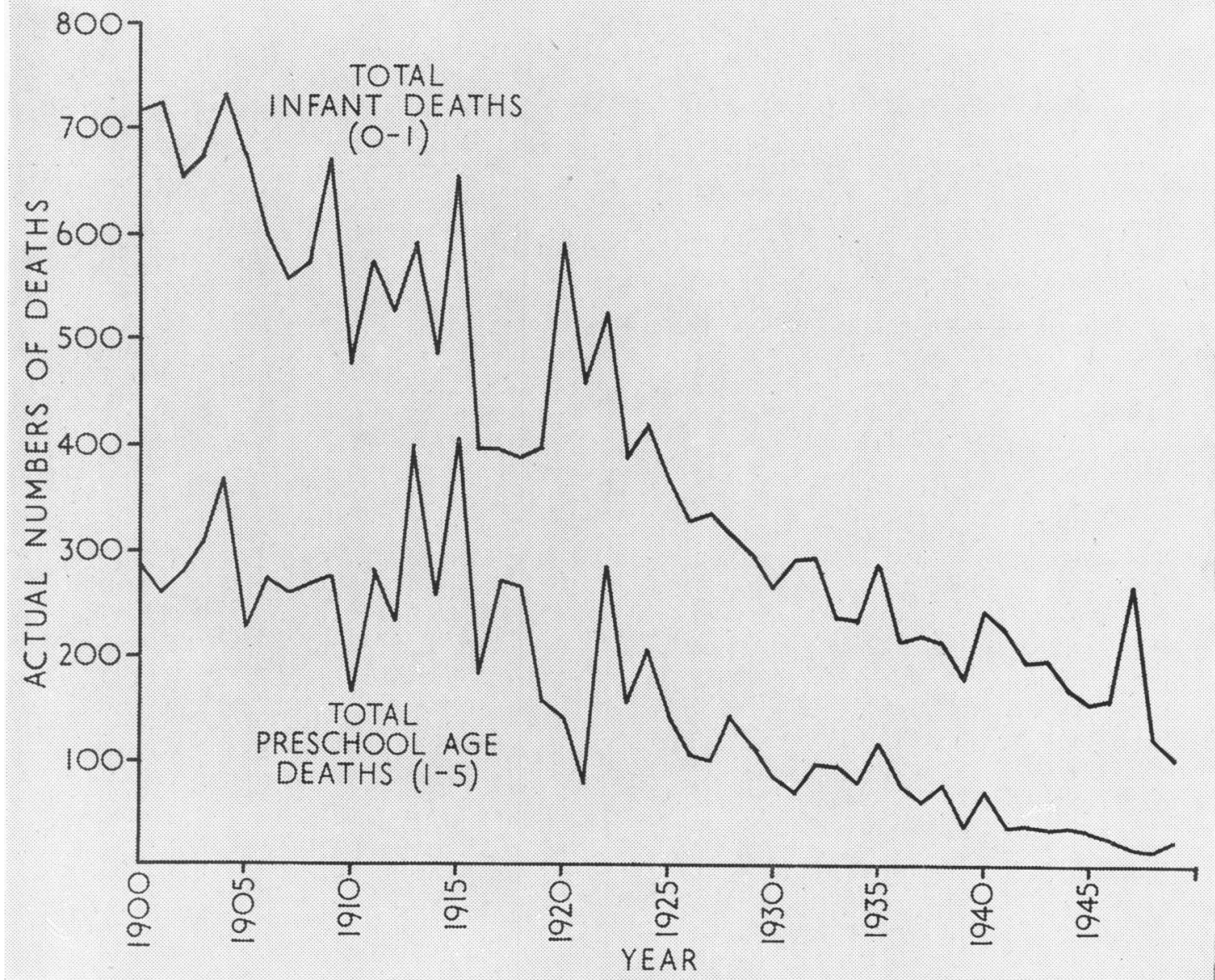

Fig. 1.-Total pre-school age deaths (1-5) and infant deaths (0-1) in the City of Aberdeen from 1900 to 1949 inclusive.

difference, when it is noted that in the first quinquennium of our period, 1,499 young children died, and in the last, only 115 . More deaths occurred, and still occur, in the second year of life than in the third, fourth, and fifth years, and the saving of lives has been greater in the earliest year of the pre-school period. Deaths in 1900 in the second, third, fourth, and fifth years of life were 169, 59, 39, and 32 respectively, whereas in 1949 they were 11 , seven, four, and one. then rife, and, in addition, scarlet fever was more prevalent than it had been since the beginning of notification in 1881 , and more frequently fatal than it had been since 1895 . The best year in the first quarter of the century, with only 80 deaths, was 1921 , when there were no deaths from measles and whooping cough, only two from scarlet fever, only five from tuberculosis, and only 17 from pneumonia and bronchitis. Figures for the following year, 1922, are very different; in that 
TABLE 3

Numbers of Deaths from Various Causes in Children between 1 and 5 years of age in Aberdeen from 1900 to 1949 INCLUSIVE

\begin{tabular}{|c|c|c|c|c|c|c|c|c|c|c|c|}
\hline 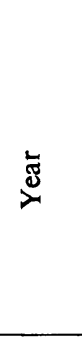 & 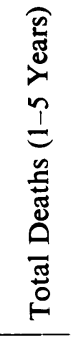 & 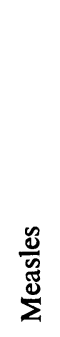 & 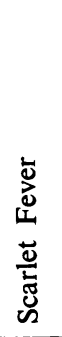 & 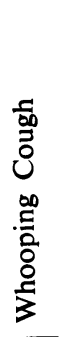 & 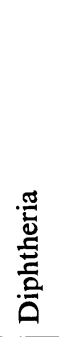 & 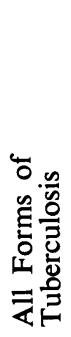 & 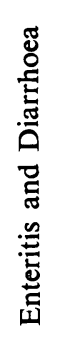 & 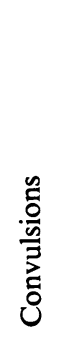 & 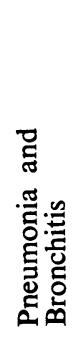 & 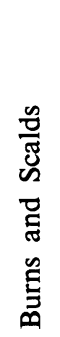 & 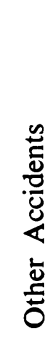 \\
\hline $\begin{array}{r}1900 \\
1 \\
2 \\
3 \\
4 \\
5 \\
6 \\
7 \\
8 \\
9 \\
1910 \\
11 \\
12 \\
13 \\
14 \\
15 \\
16 \\
17 \\
18 \\
19 \\
1920 \\
21 \\
22 \\
23 \\
24 \\
25 \\
26 \\
27 \\
28 \\
29 \\
1930 \\
31 \\
32 \\
33 \\
34 \\
35 \\
36 \\
37 \\
38 \\
39 \\
1940 \\
41 \\
42 \\
43 \\
44 \\
45 \\
46 \\
47 \\
48 \\
49\end{array}$ & $\begin{array}{r}289 \\
261 \\
277 \\
305 \\
367 \\
226 \\
268 \\
260 \\
268 \\
273 \\
167 \\
285 \\
232 \\
400 \\
259 \\
405 \\
182 \\
270 \\
267 \\
159 \\
144 \\
80 \\
284 \\
156 \\
207 \\
143 \\
105 \\
101 \\
142 \\
113 \\
85 \\
69 \\
98 \\
94 \\
80 \\
118 \\
77 \\
62 \\
78 \\
38 \\
70 \\
39 \\
39 \\
34 \\
36 \\
34 \\
25 \\
19 \\
14 \\
23\end{array}$ & $\begin{array}{r}38 \\
34 \\
55 \\
65 \\
65 \\
20 \\
42 \\
21 \\
30 \\
24 \\
1 \\
72 \\
25 \\
90 \\
4 \\
95 \\
5 \\
59 \\
30 \\
1 \\
24 \\
0 \\
93 \\
28 \\
34 \\
11 \\
11 \\
0 \\
29 \\
0 \\
12 \\
3 \\
10 \\
4 \\
4 \\
15 \\
1 \\
0 \\
11 \\
0 \\
8 \\
2 \\
0 \\
1 \\
0 \\
2 \\
0 \\
0 \\
1 \\
1 \\
0\end{array}$ & $\begin{array}{r}6 \\
6 \\
7 \\
6 \\
15 \\
9 \\
2 \\
2 \\
9 \\
7 \\
4\end{array}$ & $\begin{array}{r}39 \\
6 \\
65 \\
22 \\
80 \\
18 \\
35 \\
34 \\
29 \\
53 \\
8 \\
32 \\
28 \\
29 \\
4\end{array}$ & $\begin{array}{r}20 \\
10 \\
9 \\
6 \\
7 \\
4 \\
12 \\
8 \\
13 \\
19 \\
17 \\
15 \\
20 \\
63 \\
71 \\
29 \\
20 \\
10 \\
13 \\
12 \\
14 \\
19 \\
9 \\
5 \\
3 \\
12\end{array}$ & $\begin{array}{r}30 \\
38 \\
46 \\
46 \\
54 \\
36 \\
53 \\
58 \\
36 \\
39 \\
30 \\
36 \\
27\end{array}$ & $\begin{array}{r}4 \\
31 \\
18 \\
34 \\
20 \\
22 \\
22 \\
24 \\
19 \\
15 \\
22 \\
18 \\
16 \\
29 \\
27\end{array}$ & 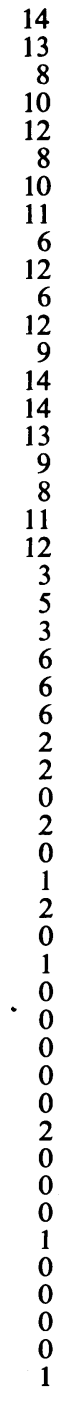 & $\begin{array}{r}72 \\
72 \\
76 \\
70 \\
67 \\
82 \\
58 \\
61 \\
62 \\
49 \\
50 \\
50 \\
53\end{array}$ & $\begin{array}{r}13 \\
14 \\
6 \\
6 \\
10 \\
5 \\
14 \\
4 \\
7 \\
4 \\
10 \\
6 \\
5 \\
10 \\
6 \\
8 \\
22 \\
13 \\
6 \\
4 \\
3 \\
0 \\
0 \\
6 \\
4 \\
3 \\
1 \\
1 \\
5 \\
8 \\
3 \\
3 \\
3 \\
2 \\
2 \\
0 \\
1 \\
2 \\
1 \\
1 \\
2 \\
2 \\
0\end{array}$ & $\begin{array}{l}3 \\
5 \\
5\end{array}$ \\
\hline
\end{tabular}


TABLE 4

Numbers of Deaths from Various Causes in Children between 1 and 5 years of age in Aberdeen in QuinQuenNial Periods from 1900 to 1949

\begin{tabular}{|c|c|c|c|c|c|c|c|c|c|c|c|}
\hline 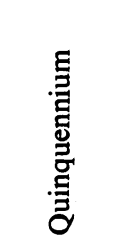 & 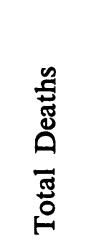 & 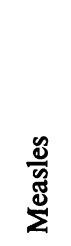 & 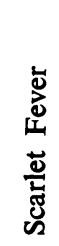 & 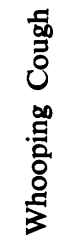 & 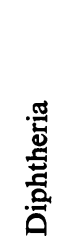 & 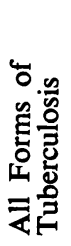 & 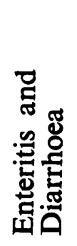 & 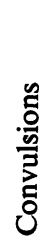 & 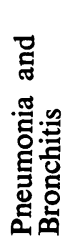 & 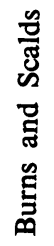 & 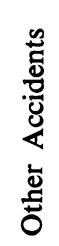 \\
\hline $\begin{array}{l}1900-04 \\
1905-09 \\
1910-14 \\
1915-19 \\
1920-24 \\
1925-29 \\
1930-34 \\
1935-39 \\
1940-44 \\
1945-49\end{array}$ & $\begin{array}{r}1,499 \\
1,295 \\
1,343 \\
1,283 \\
871 \\
604 \\
426 \\
373 \\
218 \\
115\end{array}$ & $\begin{array}{r}207 \\
137 \\
192 \\
190 \\
179 \\
51 \\
34 \\
27 \\
11 \\
3\end{array}$ & $\begin{array}{r}40 \\
29 \\
71 \\
106 \\
12 \\
17 \\
9 \\
9 \\
1 \\
1\end{array}$ & $\begin{array}{r}212 \\
169 \\
101 \\
118 \\
105 \\
72 \\
45 \\
27 \\
12 \\
3\end{array}$ & $\begin{array}{r}52 \\
56 \\
186 \\
84 \\
52 \\
41 \\
25 \\
59 \\
34 \\
5\end{array}$ & $\begin{array}{r}214 \\
222 \\
161 \\
192 \\
116 \\
96 \\
56 \\
19 \\
34 \\
13\end{array}$ & $\begin{array}{r}107 \\
102 \\
112 \\
94 \\
32 \\
26 \\
12 \\
10 \\
9 \\
5\end{array}$ & $\begin{array}{r}57 \\
47 \\
55 \\
53 \\
23 \\
12 \\
4 \\
0 \\
0 \\
3 \\
1\end{array}$ & $\begin{array}{r}357 \\
312 \\
251 \\
255 \\
168 \\
163 \\
135 \\
96 \\
48 \\
18\end{array}$ & $\begin{array}{r}39 \\
32 \\
59 \\
13 \\
15 \\
22 \\
7 \\
6\end{array}$ & $\begin{array}{l}19 \\
12 \\
20 \\
22 \\
30 \\
18 \\
16 \\
13\end{array}$ \\
\hline
\end{tabular}

year the total deaths in pre-school children rose to 284.

\section{Deaths from Various Causes}

The common infectious diseases were the fatal ones throughout the half century, and the general fall in the deaths is largely due to the lessened mortality from these diseases. In 1949 there was not a single death from measles, scarlet fever, whooping cough, or diphtheria.

Measles. This disease was one of the 'captains of the men of death' until the 20s. It has, unfortunately, not been compulsorily notifiable in our region since 1903, and the numbers of cases can only be assessed on the basis of information from the Education Authority. But it appears that it has been occurring here as elsewhere in epidemics every two to three years, as new groups of susceptible children grew up, and these occasions are shown by the increased mortality rates (Table 3 and Fig. 2) of the epidemic years. Although the disease still affects most children sooner or later, it is not as mortal as it was. For example, in 1940, an epidemic year, there were 1,571 known cases at all ages in Aberdeen with 12 deaths (eight in pre-school children), whereas in 1922, another epidemic year,

TABLE 5

Numbers of Deaths from Different Forms of Tuberculosis in Quinguennial Periods from 1900 to 1949

\begin{tabular}{|c|c|c|c|c|c|c|}
\hline Quinquennium & & Total & $\begin{array}{l}\text { Brain and } \\
\text { Meninges }\end{array}$ & Abdomen & Lungs & Other Forms \\
\hline $\begin{array}{l}1900-04 \\
1905-09 \\
1910-14 \\
1915-19 \\
1920-24 \\
1925-29 \\
1930-34 \\
1935-39 \\
1940-44 \\
1945-49\end{array}$ & $\begin{array}{l}. . \\
. \\
. \\
. \\
. \\
. \\
. \\
. \\
.\end{array}$ & $\begin{array}{r}214 \\
222 \\
161 \\
192 \\
116 \\
96 \\
56 \\
19 \\
34 \\
13\end{array}$ & $\begin{array}{r}111 \\
108 \\
82 \\
80 \\
59 \\
52 \\
29 \\
9 \\
26 \\
8\end{array}$ & $\begin{array}{r}46 \\
60 \\
39 \\
59 \\
24 \\
26 \\
9 \\
4 \\
0 \\
1\end{array}$ & $\begin{array}{r}32 \\
32 \\
21 \\
39 \\
13 \\
7 \\
5 \\
3 \\
4 \\
3\end{array}$ & $\begin{array}{r}25 \\
22 \\
19 \\
14 \\
20 \\
11 \\
13 \\
3 \\
4 \\
1\end{array}$ \\
\hline
\end{tabular}


there were 3,684 cases with 142 deaths (93 in preschool children). Since 1942 there have been only four deaths from measles in pre-school children, three of which occurred in the second year of life. children. The case mortality was $7 \cdot 7 \%$, nearly three times the average rate for the preceding 10 years. Since then the yearly death rate from scarlet fever has been low, several hundred cases have

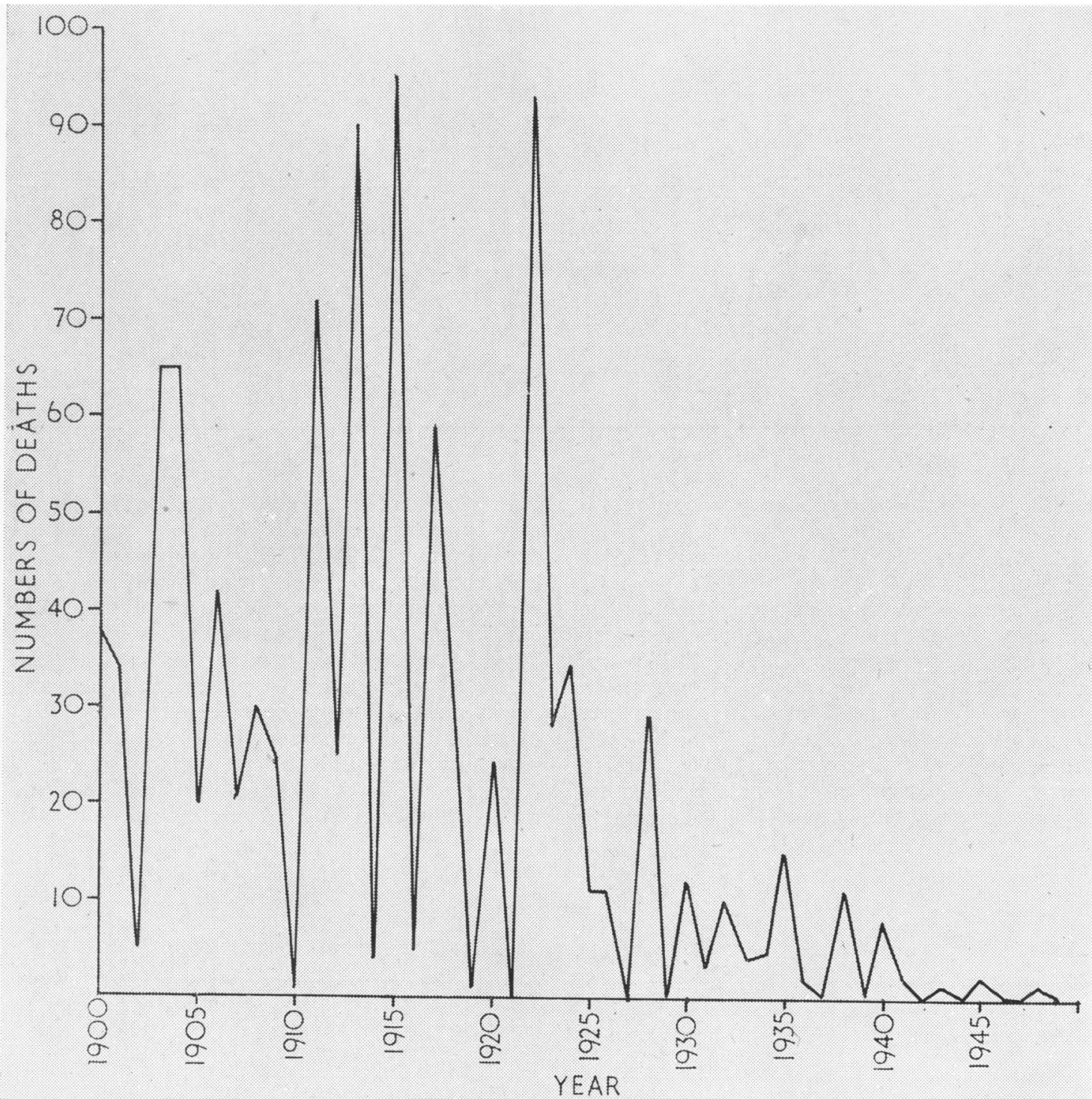

Fig. 2.-Deaths from measles in pre-school children (1-5) in the City of Aberdeen from 1900 to 1949 inclusive.

Scarlet Fever. The incidence and mortality of this disease have varied throughout 50 years. It was very prevalent from 1911 to 1915 . In the latter year there were 1,873 cases at all ages with 142 deaths, 82 of which were deaths of pre-school occurred each year, about one-quarter to one-third of them in the age group under review, but, as will be seen from Table 3 and Fig. 3, the deaths have been few. Even in 1934, an epidemic year, there were 2,122 cases of scarlet fever at all ages 
with 16 deaths, and of these 546 cases were in preschool children with only two deaths. The variations in the prevalence and in the mortality of this disease have been independent of therapy, isolation, and medical attention, and would appear to be due to biological changes in the organism. The treatment by sulphonamides and penicillin may in some epidemic years. The mortality is now very low, and only about one child a year now dies from the disease in the pre-school age group. The mortality rate was falling before the introduction of sulphonamides and the antibiotics, but has certainly been lower since. These materials may have contributed to the present very low rate.

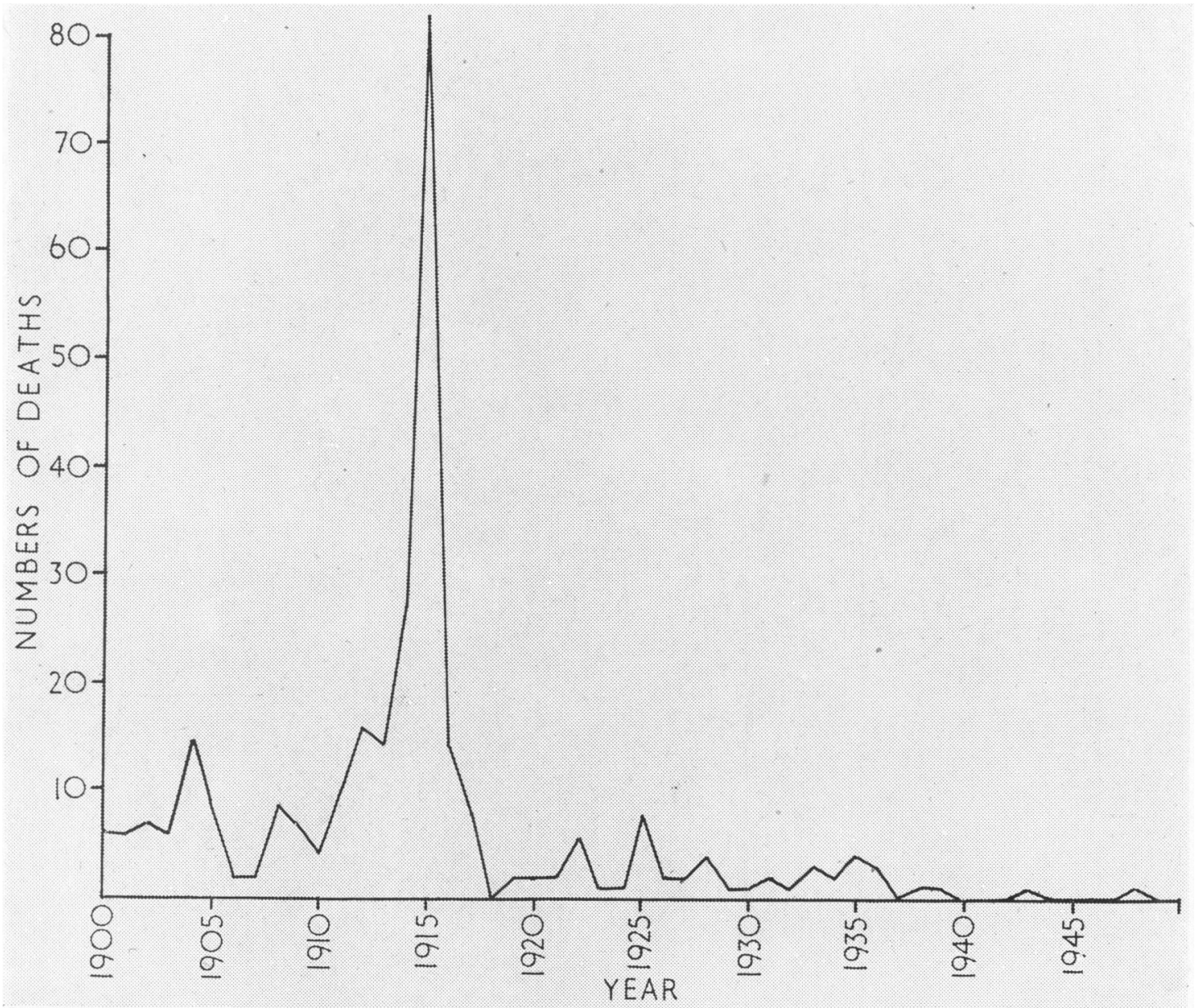

Fig. 3.-Deaths from scarlet fever in pre-school children (1-5) in the City of Aberdeen from 1900 to 1949 inclusive.

have contributed a little to the almost complete absence of mortality since 1937.

Whooping Cough. This behaves epidemiologically (Table 3 and Fig. 4) like measles, and attacks many children at pre-school age. It has not been compulsorily notifiable in Aberdeen since 1903, but it is known that epidemics have been occurring every two to three to four years. Several hundred cases occur in most years, and over 1,000 cases are known
Diphtheria. Diphtheria accounted for many deaths in the first 25 years despite the fact that antitoxin was free and widely used after 1906 . In each of the first 10 years of the century about 300 cases of diphtheria occurred at all ages, and in 1913 and 1914 there were 2,062 and 1,627 cases respectively. The great increase in the deaths in 1913 and 1914 in pre-school children will be noted (Table 3 and Fig. 5). The former year was a bad one 
with the simultaneous prevalence of measles, whooping cough, and diphtheria, and an increase in deaths from tuberculosis. The deaths from diphtheria both in 1913 and 1914 were spread over the four years of the pre-school age; the 63 deaths in 1913 being 19, 19, 13, and 12; and the 71 in 1914 being $16,19,16$, and 20 in the second, third, fourth,
The incidence of the disease, of which 586 cases were notified in 1940, began to fall in 1941, and more acutely in 1943, but there were still 136 cases at all ages in 1945 including 49 pre-school children of whom five died. In the following year, 1946, only 68 cases occurred, 17 in pre-school children, and for the first time there was not a single death

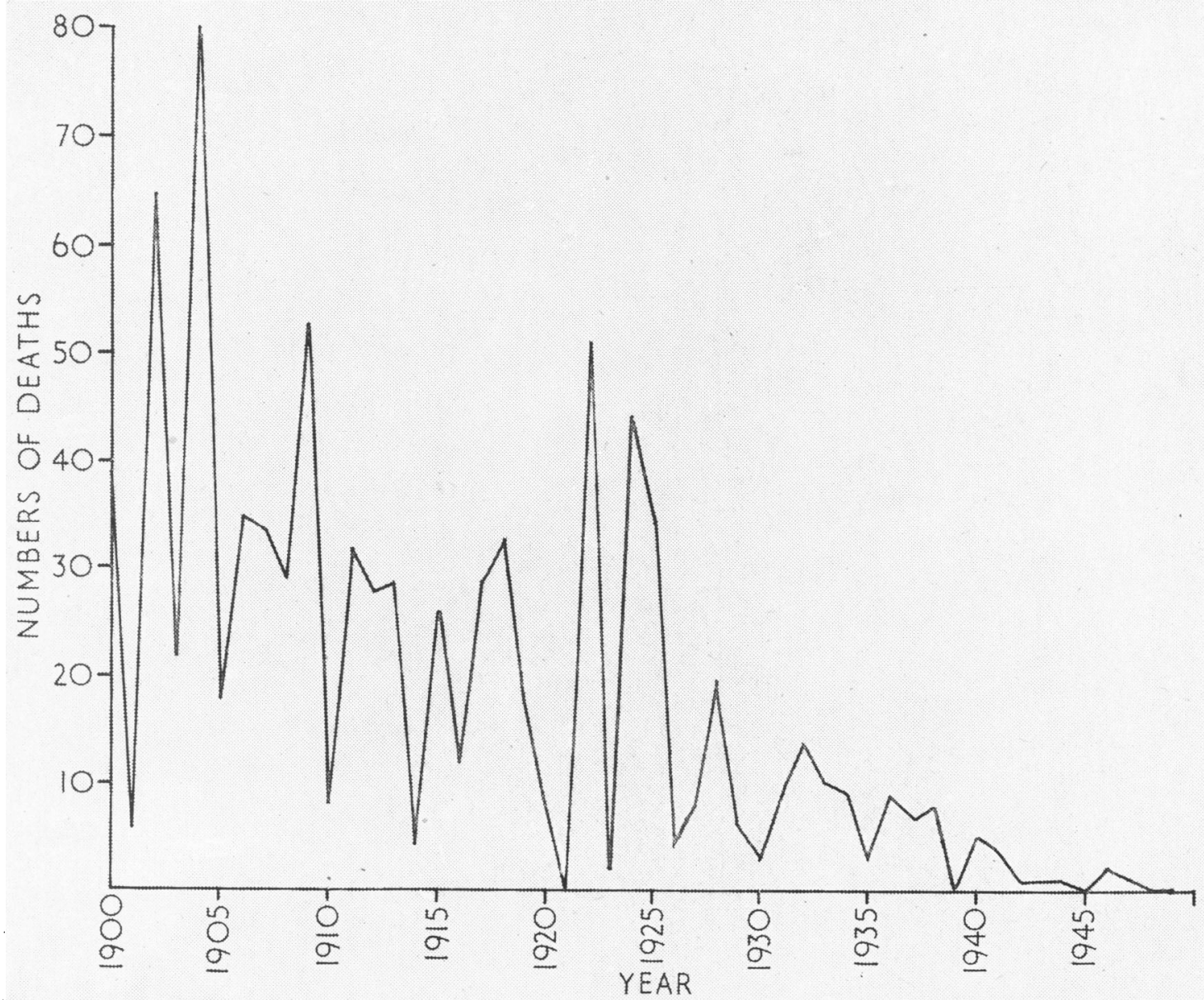

Fig. 4.-Deaths from whooping cough in pre-school children (1-5) in the City of Aberdeen from 1900 to 1949 inclusive.

and fifth years respectively. Active immunization was tentatively begun from 1921 to 1923 , and was reintroduced more widely in 1936 at the welfare centres, the nursery schools and at the City (Fever) Hospital, but there was no difference in the attack incidence in the child population. Free and increased facilities were provided after 1940, and by the middle of $1945,25 \%$ of pre-school children were immunized fully, and a further $4 \%$ had received one inoculation. from the disease. By this time $90 \%$ of the school children were known to be fully immunized against diphtheria; and $40 \%$ of the infants and children between 6 months and 5 years of age. Only nine cases were notified in 1947 (three in pre-school children), and four in 1948 of whom only one was a child aged 2 years and not immunized. No deaths occurred. By the end of $1948,92 \cdot 3 \%$ of school children had been immunized (and many thousands had been reinoculated), and $55 \cdot 5 \%$ of pre-school 
children had been similarly protected. There appears to be no doubt whatever of the value of active immunization against diphtheria when it is carried out in practically every infant and child.

Tuberculosis. For a long time tuberculosis was a common cause of death in pre-school children, and it will be seen from Tables 3 and 5 and Fig. 6
The fall increased in the middle 30 s and continued with only a slight lag in the war years, 1942 to 1944 . This fall has influenced the mortality rates for all forms of tuberculosis: meningeal, abdominal, respiratory, and other forms. During the last ten years there has been only one death from abdominal tuberculosis. This may be related

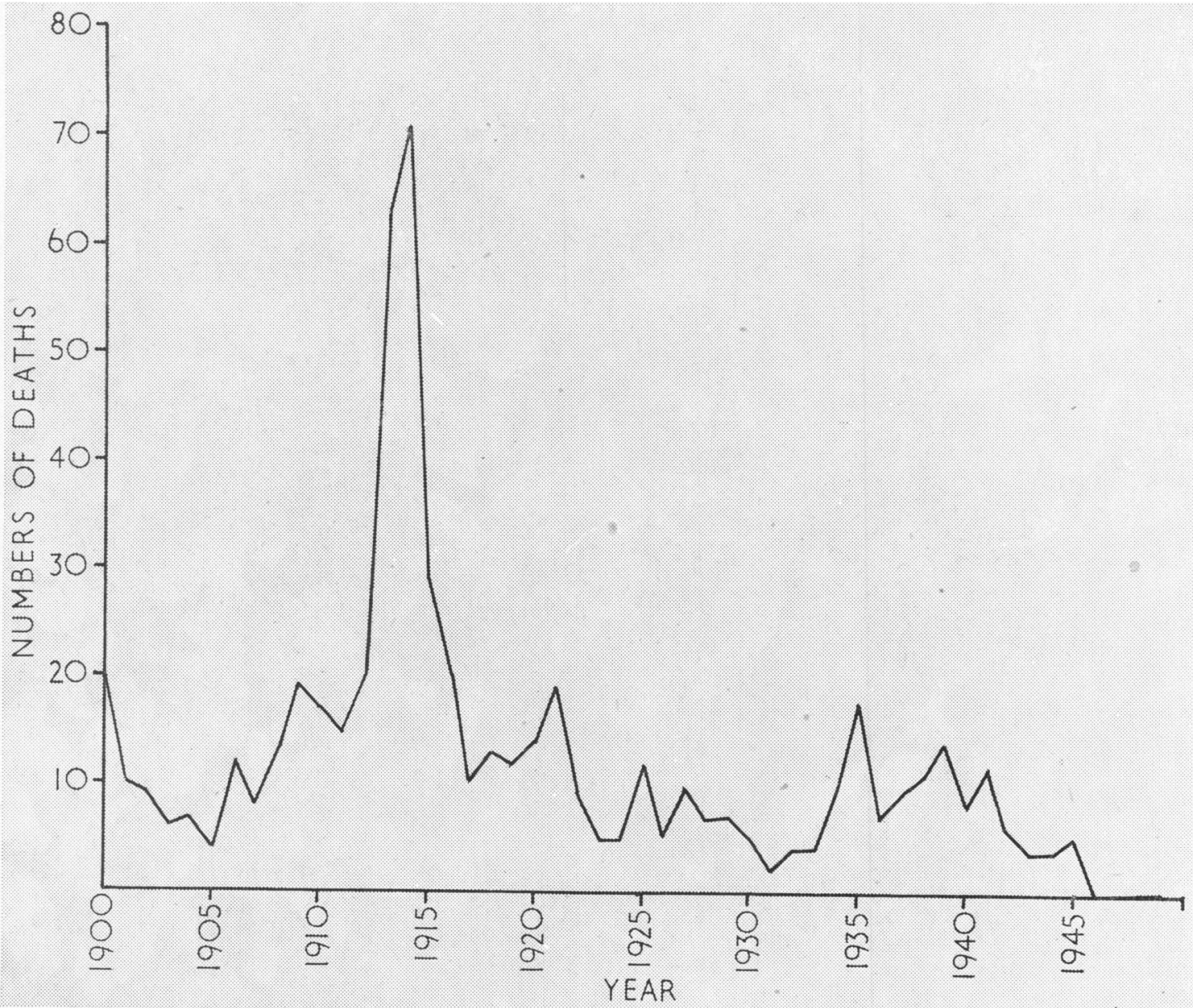

Fig. 5.-Deaths from diphtheria in pre-school children (1-5) in the City of Aberdeen from 1900 to 1949 inclusive.

that the rate did not begin to fall appreciably until the 1920s. Even then there was a tendency for the rate to rise with the rise in measles and whooping cough, an association that is well known. It has already been noted that in 1921 there were no deaths from measles or whooping cough. In the same year there were only five deaths from tuberculosis. In 1939 there were no deaths from measles and whooping cough, and no deaths at all from any form of tuberculosis. to the pasteurization of milk which became general in the City in 1940, to the distribution of such milk to children under 5 years old, and to the use by infants of dried milk and vitamin supplements which became general after August, 1940.

Enteritis and Diarrhoea. This heading represents an ill-defined group, and probably included various diseases, such as dysentery and non-specific enteritis. The diseases in the group have not-been an important cause of death for the last 30 years, 
although there were in the City small epidemics of Flexner dysentery from time to time, and Sonne dysentery has been endemic for many years. There have been a few years, for example, 1940 and 1947, when infantile gastroenteritis was epidemic, and the cause of many deaths in the first year of life.

'Convulsions.' This is an unsatisfactory term
Pneumonia and Bronchitis. I have put these two diseases together for it is usually found that a young child veryill with supposed bronchitis has pneumonia on radiographic examination or at necropsy. These respiratory deaths were common; and although they fell in numbers steadily throughout the 50 years (Table 3 and Fig. 7), the fall was

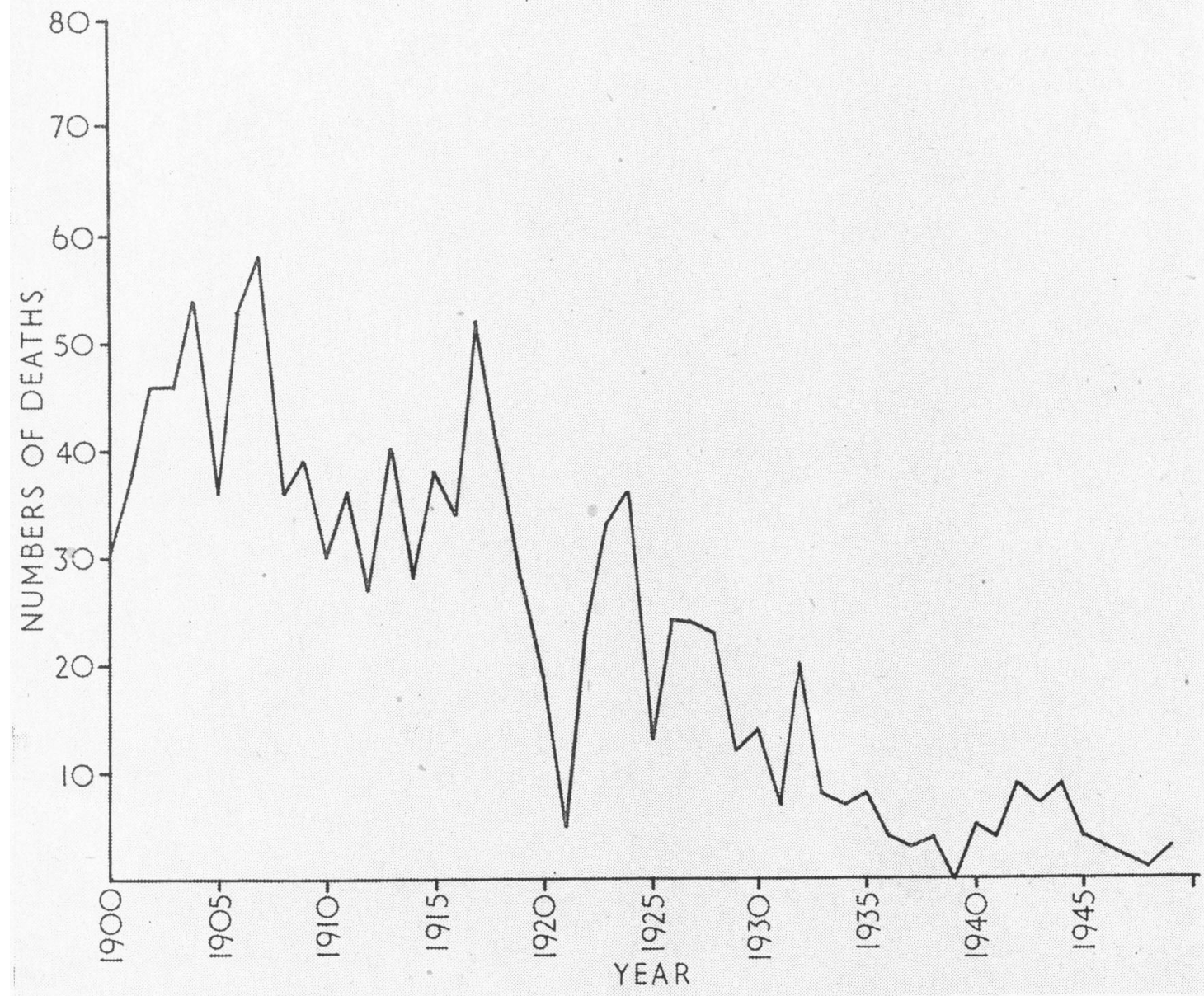

FIG. 6.-Deaths from all forms of tuberculosis in pre-school children (1-5) in the City of Aberdeen from 1900 to 1949 inclusive.

when given as a certified cause of death, for 'convulsions' are only symptoms of many diseases, including the common infectious ones. However, I can find no correlation between deaths from these and the incidence of mortal convulsions. They fell rather abruptly as a cause of death in the 1920s, and it is possible that the fall was due to the lessened numbers of spasmophilic convulsions and of rickets that were seen after that time. accentuated after 1938, and again during the last six years. It will be noted that the deaths rise in the years when measles is prevalent; that there was a rise in 1918 when influenza was pandemic; and that in 1929 there was also an increase. In this year there was a rise in pneumonia notifications at all ages to about twice the normal, due to an epidemic of 'influenza' in the early part of the year. The lowered death rates in recent years 
may be partly due to the newer drugs and antibiotics.

Accidental Deaths. The progress of accidental deaths has varied. It will be seen that deaths from burns and scalds have fallen greatly, especially in the last 10 years. I doubt if this can be attributed entirely to a smaller number of cases, for the
Summary

The deaths in young children in the second, third, fourth, and fifth years of life in the City of Aberdeen during the 50-year period from 1900 to 1949 inclusive have been studied. The actual numbers of deaths have been used instead of death rates, as no age group estimates were compiled for local areas

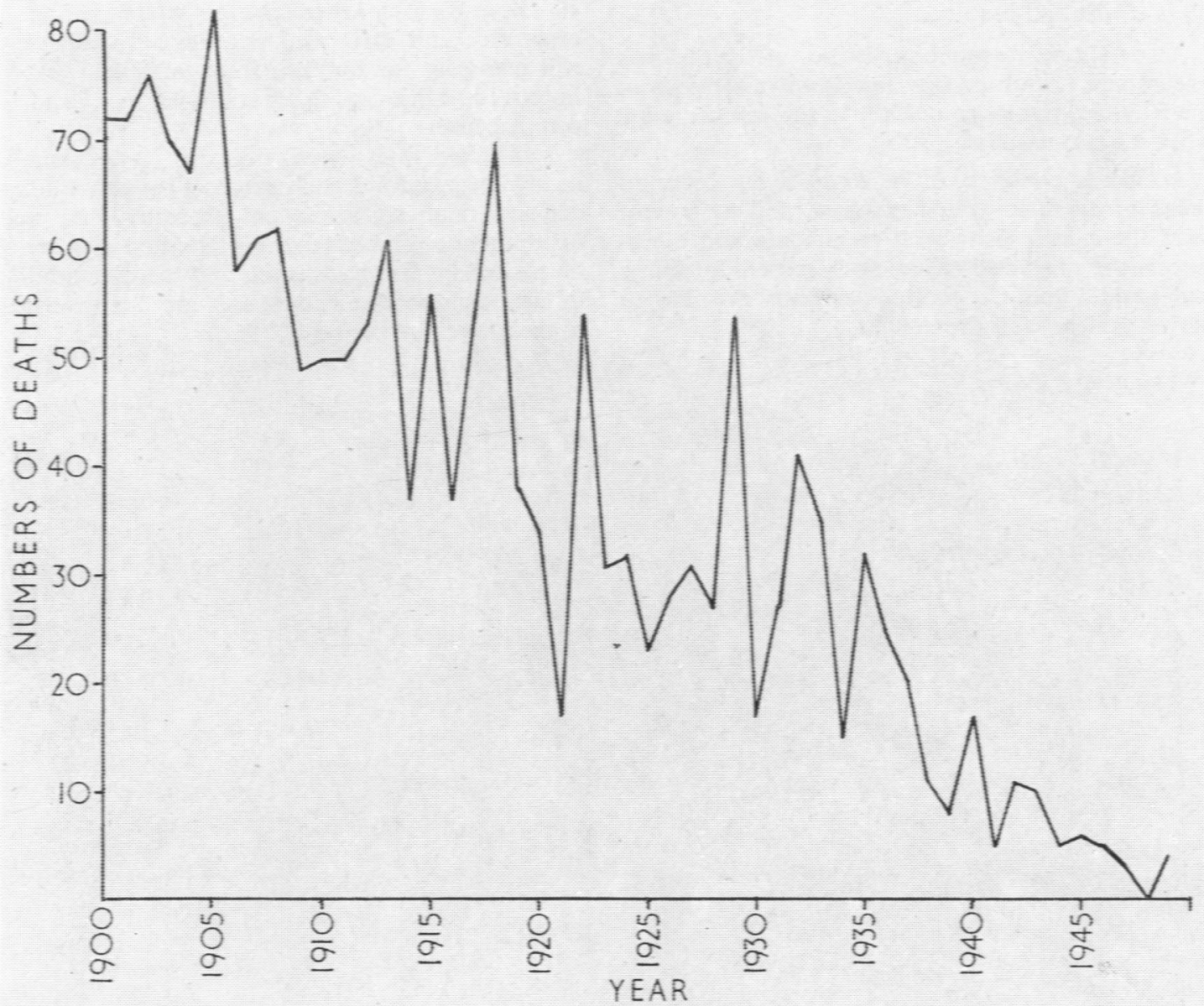

FiG. 7.-Deaths from pneumonia and bronchitis in pre-school children (1-5) in the City of Aberdeen from 1900 to 1949 inclusive.

incidence of burns and scalds admitted to hospital has not fallen proportionately. It seems likely that better treatment (by drugs and antibiotics and by the giving of plasma) is responsible. Other accidents, now mainly from motor vehicles and from drowning, are not falling, and they remain one of the common causes of preventable deaths. in Scotland later than 1930. Further, the actual numbers probably give a better picture of the progress of the different mortal diseases.

There has been a striking fall in the total deaths, largely owing to lowered mortality from measles, whooping cough, pneumonia, and tuberculosis. Diphtheria is no longer a common cause of death; indeed, the disease has almost disappeared. Scarlet 
fever is at present a mild disease. So great has been the fall in the mortality of the infectious diseases that in 1949 there was not a single death in young children in Aberdeen from measles, whooping cough, scarlet fever, or diphtheria.

Deaths from tuberculosis are now mainly due to meningitis, the end-result of a primary lung infection; and deaths from abdominal tuberculosis are so rare that there was only one in the last 11 years of the half-century.

A persistently common cause of death was pneumonia. Its mortality fell steadily throughout the 50 years, but more quickly in the last six years when it has caused few deaths.

Accidents continue to be a relatively common cause of death in young children, and at present head the causes along with pneumonia and tuberculosis. Fewer deaths are now caused by burns and scalds, and the mortal accidents are due to motor vehicles and drowning.
There are probably many reasons for the lowered mortality rates. Diphtheria is almost certainly prevented by immunization; and the antibiotics and the sulphonamide group of drugs have lowered the death rates from primary and secondary pneumonia. Abdominal tuberculosis is avoided by using milk free from living tubercle bacilli. Some of the steady improvement throughout the 50 years may be due to improvement in living conditions, but there may also have been biological changes in the pathogenic organisms and their victims. Eternal vigilance is still necessary for freedom from infection, and the improved mortality figures should not lead to complacency.

Mortality rates give no real indication of morbidity; and although deaths in young children are now relatively infrequent, these children make up about one-third of the cases admitted to hospitals or treated by family doctors, and many conditions in later childhood, e.g. deafness, are due to disease in the pre-school period of life. 